\title{
Digit Span Sequencing Subtest (WAIS-IV)
}

National Cancer Institute

\section{Source}

National Cancer Institute. Digit Span Sequencing Subtest (WAIS-IV). NCI Thesaurus. Code C120518.

A subtest of the Wechsler Adult Intelligence Scale - Fourth Edition. The subject is read a sequence of numbers and recalls the numbers in ascending order. 